\title{
A Review Paper on Deep Learning Approach for Crop Yield Prediction Assessment
}

\author{
Richa Verma ${ }^{1} \mid$ Ayushi $^{2}$
}

Research Scholar, Department of Computer Science Engineering, Hindu College of Engineering, Sonipat (Haryana). Assistant Professor, Department of Computer Science Engineering, Hindu College of Engineering, Sonipat (Haryana).

\section{To Cite this Article}

Richa Verma \& Ayushi. A Review Paper on Deep Learning Approach for Crop Yield Prediction Assessment. International Journal for Modern Trends in Science and Technology 7, 127-132 (2021).

\section{Article Info}

Received on 26-April-2021, Revised on 08-May-2021, Accepted on 12-May-2021, Published on 20-May-2021.

\section{ABSTRACT}

Precise assessment of harvest yield is a difficult field of work. The equipment and programming stage to foresee the harvest yield relies on different components like climate, soil fruitfulness, genotype, and different collaborating wards. The assignment is unpredictable inferable from the information that should be gathered in volumes to comprehend crop yield through remote sensor organizations and distant detecting. This paper audits the previous 15 years of exploration work in the improvement of assessing crop yield utilizing profound learning calculations. The meaning of examining progressions utilizing profound learning methods will help in dynamic for foreseeing the harvest yield. The cross breed mix of profound learning with distant detecting and remote sensor organizations can give accuracy agribusiness later on.

KEYWORDS: Decision Making, Feature Extraction, Deep Learning, Remote Sensing, Wireless Sensor Networks

\section{INTRODUCTION}

The test of agrarian maintainability has gotten more serious lately with the sharp ascent in the expense of food and energy, environmental change, water shortage, debasement of characteristic biological systems and biodiversity, the monetary emergency and anticipated expansion in populace. With expanding requests for food and horticultural items, heightening of smallholder creation framework turns out to be progressively essential. As of late, horticultural advances which increment food creation reasonably simultaneously offering environmental change transformation and alleviation advantage on the whole known as environment shrewd rural (CSA) rehearses have been the subject of logical examination. CSA rehearses are intended to accomplish horticultural supportability by execution of economical administration rehearses that limit ecological corruption and ration assets while keeping up high-yielding, productive frameworks, and furthermore improve the organic elements of the agro-biological systems. Notwithstanding, synchronous evaluation of profitable, versatile and relieve creation frameworks is as yet insufficient and dissipated [1]. Another exploration that evaluated the effect of worldwide temperature change on crop yield has discovered the creation of wheat-a significant piece of diets around the world-will decrease as temperatures increment. Simultaneously, the interest for wheat is required to increment by $60 \%$ by the center of the 21 st century, according to the Food and Agriculture Organization (FAO).

Farming assumes an essential part in India's economy. $54.6 \%$ of the populace is occupied with 
farming and associated exercises (enumeration 2011 ) and it contributes $17.4 \%$ to the nation's Gross Value Added (GVA) for the year 2016-17 (at current costs). According to the land use measurements 2014-15, absolute geological space of the nation is 328.7 million hectares, of which announced net planted region is 140.1 million hectares and the gross trimmed region is 198.4 million hectares with an editing force of $142 \%$. The net region planted works out to be $43 \%$ of the complete geological region. The net watered region is 68.4 million hectares[2].

There has been a nonstop decrease in the portion of farming and unified areas in the GVA from percent in 2013-14 to 17.4 percent in 2016-17. Falling portion of horticulture and partnered areas in GVA is a normal result in a quickly developing and basically evolving economy.

The powerful observing of harvest is a half and half framework, where central point influencing crop yield is appeared in the Figure. 1. All in all, crop yield is anticipated by noticing numerous variables, for example, water use, estate territory, soil quality, climate conditions, sickness events, etc [5-7]. Thinking about the top variables in the Figure. 1., climate checking, soil boundaries and harvest region are considered for the examination. The factor identified with measure the information can be assembled by utilizing designing advances, for example, remote sensor organizations, distant detecting, and so forth. India is the top producer of various harvests in the world. There can be various ways to deal with independent such yields (considering district, season, money related worth, etc) considering seasons; the harvests in India are parceled into three sorts:
i) Rabi
ii) Kharif and
iii) Zaid.

Fig: 1 shows the various factors affecting yield prediction of crop.

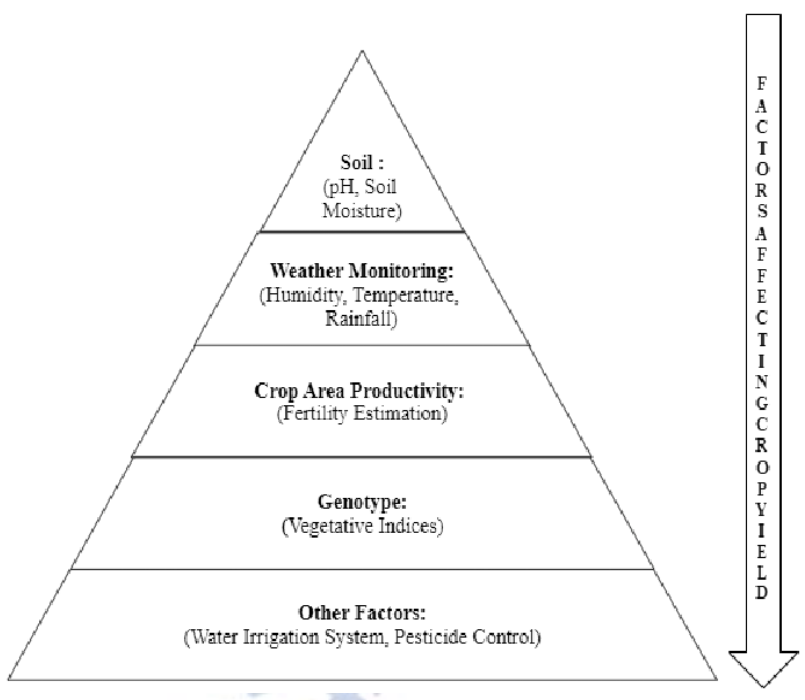

Fig: 1 Various factors affecting yield prediction of crop

Table 1 shows the yield assortments partitioned based on periods of India.

Table 1: Crop Varieties on the basis of Season as in India [3].

\begin{tabular}{|c|c|c|c|}
\hline $\begin{array}{l}\text { Crop } \\
\text { Type }\end{array}$ & $\begin{array}{c}\text { Sowing } \\
\text { Season } \\
/ \\
\text { Harvest } \\
\text { Season }\end{array}$ & $\begin{array}{c}\text { Environment } \\
\text { Conditions } \\
\text { Required }\end{array}$ & Crop Names \\
\hline Kharif & $\begin{array}{l}\text { June-Juny } \\
\text { / Sept.Oct. }\end{array}$ & $\begin{array}{c}\text { Requires lot of } \\
\text { water } \\
\text { and hot weather } \\
\text { to } \\
\text { grow. }\end{array}$ & $\begin{array}{c}\text { Rice, Jowar, } \\
\text { Bajra, } \\
\text { Maize, Cotton, } \\
\text { Groundnut, Jute, } \\
\text { Sugarcane, } \\
\text { Turmeric, } \\
\text { Pulses } \\
\text { (like } \\
\text { Urad } \\
\text { Dal). }\end{array}$ \\
\hline Rabi & $\begin{array}{l}\text { Oct.-Nov./ } \\
\text { April-May. }\end{array}$ & $\begin{array}{c}\text { Requires warm } \\
\text { climate } \\
\text { for germination } \\
\text { of seeds } \\
\text { and maturation } \\
\text { and cold } \\
\text { climate for the } \\
\text { growth. }\end{array}$ & $\begin{array}{l}\text { Wheat, Oat, } \\
\text { Gram, } \\
\text { Pea, Barley, } \\
\text { Potato, } \\
\text { Tomato, Onion, } \\
\text { Oil } \\
\text { Seeds (like } \\
\text { Rapeseed, } \\
\text { Sunflower, } \\
\text { Sesame, } \\
\text { Mustard). }\end{array}$ \\
\hline Zaid & $\begin{array}{l}\text { March-Jun } \\
\text { e beetween } \\
\text { Rabi and } \\
\text { Kharif / } \\
\text { Early } \\
\text { Maturing } \\
\text { Crops. }\end{array}$ & $\begin{array}{l}\text { Requires warm } \\
\text { and dry } \\
\\
\text { weather for } \\
\text { growth and } \\
\text { longer day } \\
\text { duration for } \\
\text { flowering. }\end{array}$ & $\begin{array}{l}\text { Gourd, Pumpkin, } \\
\text { Watermelon, } \\
\text { Muskmelon, } \\
\text { Moong } \\
\text { Dal. }\end{array}$ \\
\hline
\end{tabular}

1.1 Crop Categories on the Basis of Usage[3]:

i. Food Crops (Wheat, Maize, Rice, Millets and Pulses and so on) 
ii. Cash Crops (Sugarcane, Tobacco, Cotton, Jute and Oilseeds and so forth)

iii. Plantation Crops (Coffee, Coconut, Tea, and Rubber and so on)

iv. Horticulture crops (Fruits and Vegetables)

\subsection{Data-Drive Model}

Information driven models are fabricated exactly, not needing profound information about actual components that delivered the information. In a distinct district, information driven models consider crop yield for a long time and successful factor on crop yield are found. At that point crop yield is identified with compelling boundary by an observational condition and the coefficient of each factor is found. Presently by these coefficients, crop yield is assessed. Each set of exact models relate crop respects one set components .In the most relations, viable variables are natural Such strategies are modest, moderately simple to apply, and needn't bother with a predefined construction of the model. Thus, information driven models have been broadly applied somewhat recently utilizing traditional insights and AI strategies Statistical models are addressed by parametric constructions tuned with amount of-squares residuals, approved by theories test and certainty spans [6].

\section{MACHINE LEARNING TECHNIQUES}

AI (ML) manages issues where the connection among info and yield factors isn't known or difficult to get. The "learning" term here signifies the programmed obtaining of underlying portrayals from instances of what is being depicted. In contrast to customary factual techniques, ML doesn't make suppositions about the right design of the information model, which depicts the information. This trademark is exceptionally valuable to display complex non-straight practices, for example, a capacity for crop yield expectation. [23]

The uses of AI are multi-disciplinary where conventional guideline based calculations are impractical to be developed or neglect to convey right outcomes. One such field is agribusiness. There are three sorts of learning calculations in machine acquiring:

\subsection{Supervised Learning}

The calculation is given some preparation models based on which it can consider the sources of info and their comparing yields. For instance, showing a youngster the banner of a country and furthermore revealing to him the name of the country it has a place with. On the off chance that the yield factors are given, the learning gets directed. Issues like arrangement and relapse go under this class. Famous managed learning calculations are Artificial neural organizations, Decision trees, K-implies grouping, Support vector machines, Bayesian organizations and so on.

\subsection{Unsupervised Learning}

At the point when the calculation isn't furnished with any yields, the learning is supposed to be solo. For instance, on the off chance that we read a book in a language that we don't have the foggiest idea, we don't get anything, yet we continue perusing or watching we will distinguish certain examples in words gradually begin understanding. Calculations including bunching methods have a place with this classification. Famous solo learning calculations are Self coordinated element maps, COBWEB, DBSCAN and so on.[24]

\subsection{Reinforcement Learning}

Such learning works on the rule of info. Every movement influences the system which is then itemized back to the estimation. The computation changes its lead as shown by the info got. Renowned computations are Genetic estimations, Markov decision estimations, etc

\section{APPLICATIONS OF MACHINE LEARNING IN AGRICULTURE}

The various utilizations of ML in the farming are to choose a harvest, yield expectation, climate forecast can help the far fog at different levels like to choose which sort of yield ought to be chosen, how to have better yield, which climate conditions are more appropriate and child. The distinctive ML methods can be used for the reasons indicated and portrayed to sum things up as follows:

\section{i. Crop Selection and Crop Yield Prediction \\ To augment the harvest yield,} determination of the fitting harvest that will be planted assumes an essential part. It relies upon different variables like the kind of soil and its organization, environment, geology of the area, crop yield, market costs and so on AI gives numerous viable calculations which can 
recognize the info and yield relationship in crop determination and yield forecast. Strategies like Artificial neural organizations, K-closest neighbors and Decision Trees have cut a specialty for themselves with regards to edit determination which depends on different elements.

\section{ii. Weather Forecasting}

Indian agribusiness essentially depends on occasional downpours for water system.[13,14] Subsequently, a precise figure of climate can decrease the huge work looked by ranchers in India including crop determination, watering and collecting. As the ranchers have helpless admittance to the Internet because of advanced gap, they need to depend on the little data accessible in regards to meteorological forecasts. Cutting-edge just as precise climate data is as yet not accessible as the climate changes powerfully after some time. Specialists have been chipping away at improving the precision of climate forecasts by utilizing an assortment of calculations. Counterfeit Neural organizations have been received widely for this reason. Similarly, climate forecast dependent on AI method called Support Vector Machines had been proposed. These calculations have shown better outcomes over the regular calculations and consequently have a splendid future for acknowledgment.[25]

\section{iii. Smart Irrigation System}

Cultivating area devours a gigantic bit of water in India. The degrees of ground water are dropping step by step and an Earth-wide temperature boost has brought about environment changes. The stream water for water system is a major issue of debate among numerous states in India.[18] To battle the shortage of water, numerous organizations have thought of sensor based innovation for keen cultivating which utilizes sensors to screen the water level, supplement content, climate figure reports and soil temperature. These brilliant gadgets are being planned on the standards of AI, working with the sensors information and improving the framework after some time without help from anyone else.[23]

iv. Crop Disease Prediction

AI techniques have been utilized in the new years for crop sickness expectation and these endeavors have been demonstrated advantageous. They uncovered higher exactness contrasted with the conventional factual techniques like relapse examination. These strategies manage uproarious and complex information. Among every one of the referenced applications, utilization of AI procedures for crop yield expectation is acquiring consideration of scientists step by step. Albeit different AI procedures have been utilized for crop yield Assessment, Artificial Neural Networks and their structures are acquiring prominence [8].

\section{DEEP LEARNING}

Connectionist models have existed for over 70 years, yet new designs and graphical preparing units (GPUs) carried them to the cutting edge of man-made brainpower. The most recent twenty years gave us profound learning models, which extraordinarily extended the number and sort of issues neural organizations can address. Profound learning comprises of profound organizations of fluctuating geographies. Neural organizations have been around for a long time, yet the advancement of various layers of organizations (each giving some capacity, for example, include extraction) made them more reasonable to utilize. Adding layers implies more interconnections and loads between and inside the layers. This is the place where GPUs advantage profound getting the hang of, making it conceivable to prepare and execute these profound organizations (where crude processors are not as productive).[22]

\subsection{Deep Learning Architectures}

The quantity of designs and calculations that are utilized in profound learning is wide and fluctuated. Table 2 shows the different models and their long stretches of starting point.

Table 2: Deep Learning Architectures and their years of origin

\begin{tabular}{|c|c|}
\hline Year & Deep Learning Architecture \\
\hline $1990-1995$ & RNN \\
\hline $1995-2000$ & LSTM \& CNN \\
\hline $2005-2010$ & DBN \\
\hline $2010-2015$ & DSN \& GRU \\
\hline
\end{tabular}

\subsubsection{Deep Neural Network(DNN)}

Profound Neural Network is a fake neural organization (ANN) with numerous secret layers between the info and yield layers. DNNs can show complex non-direct connections. DNN structures create compositional models 
where the article is communicated as a layered synthesis of natives.[16] The additional layers empower creation of highlights from lower layers, possibly demonstrating complex information with less units than a comparatively performing shallow organization. Profound structures incorporate numerous variations of a couple of essential methodologies. Every engineering has discovered accomplishment in explicit areas.[19] It isn't generally conceivable to think about the presentation of various models, except if they have been assessed on similar informational collections. DNNs are ordinarily feed forward networks in which information streams from the info layer to the yield layer without circling back. Fig. 2 shows the Deep Natural Networks. [21]

\section{Deep Neural Network (DNN)}

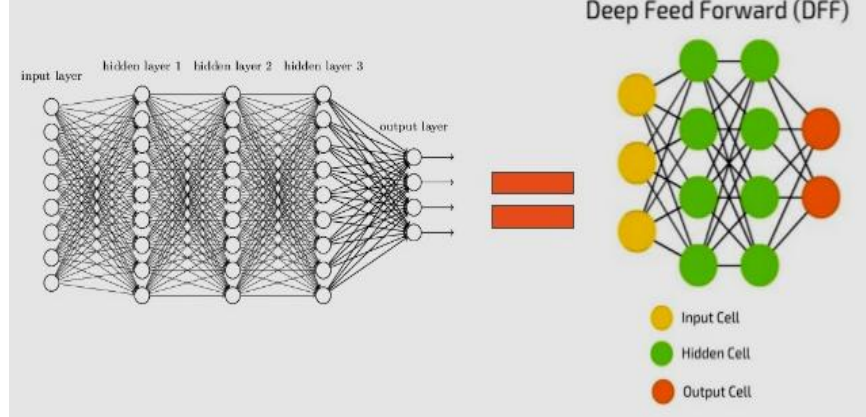

Fig: 2 Deep Natural Networks (DNN)

\subsubsection{Convolutional Neural Network(CNN)}

Convolution Neural Networks are basically the same as normal Neural Networks, they are comprised of neurons that have learnable loads and inclinations. In convolutional neural organization (CNN, or ConvNet or shift invariant or space invariant) the unit network design is roused by the association of the visual cortex, Units react to upgrades in are stricter district of room known as the responsive field. Responsive fields part of the way cover, over-covering the whole visual field. Unit reaction can be approximated numerically by a convolution activity. They are varieties of multi-facet insights that utilization insignificant preprocessing. Their wide applications is in picture and video acknowledgment, recommender frameworks and regular language handling. CNNs require enormous information to prepare on. [20]Fig.3 shows Convolution Neural Network (CNN)

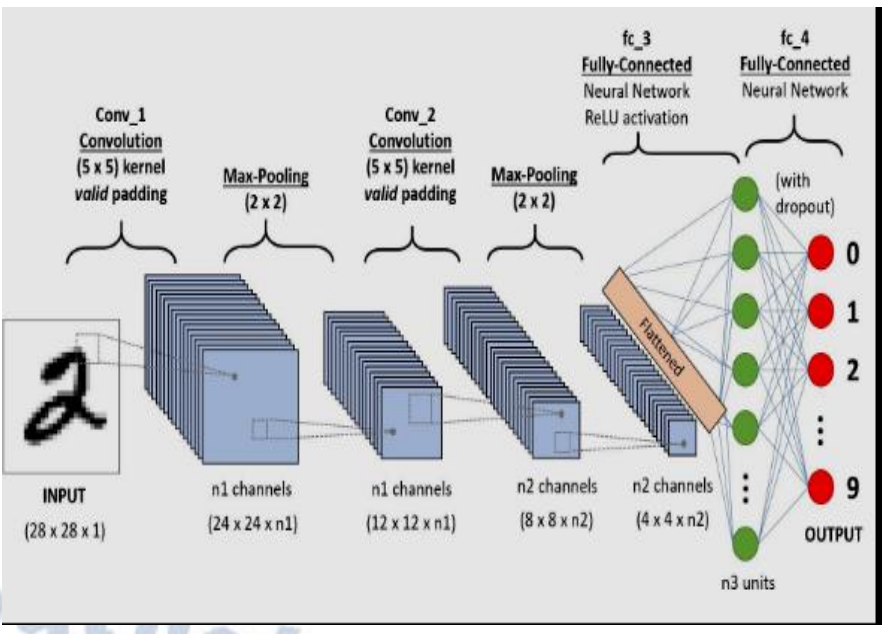

Fig: 3 Convolution Neural Network (CNN)

\subsubsection{Recurrent Neural Networks (RNN)}

In intermittent neural organization (RNN), associations between units structure a coordinated cycle (they engender information forward, yet additionally in reverse, from later handling stages to prior stages). This permits it to display dynamic fleeting conduct. In contrast to take care of forward neural organizations, RNNs can utilize their inside memory to deal with self-assertive arrangements of data sources. This makes them pertinent to assignments like unregimented, associated penmanship acknowledgment, discourse acknowledgment and other general arrangement processors. Fig: 4 Shows Recurrent Neural Network Structure

\section{Recurrent Neural Network structure}

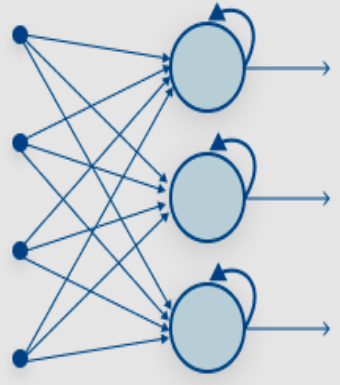

Recurrent Neural Network

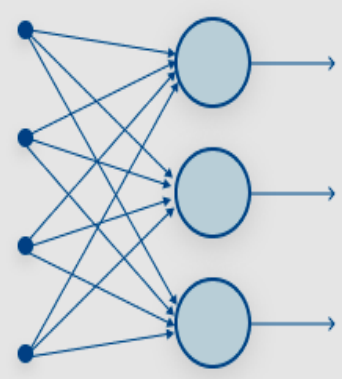

Feed-Forward Neural Network
Fig 4 Recurrent Neural Networks(RNN)

\section{OBJECTIVES}

- To study existing examination papers in the field

- To investigate another part of ANN i.e., profound learning, to foresee crop yields with exactness. 
- Among different profound learning models, RNN will be investigated around there.

- We will play out an itemized correlation with previously existing models

\section{CONCLUSION}

The interest for horticulture food creation is expanding quickly, and without utilizing current innovations; odds are less to satisfy the agro need of the populace. Preposterous decade, the different mechanical applications utilizing profound learning has acquired positive exactness factor. The current paper surveys profound learning calculations in anticipating crop yield utilizing the boundaries like: climate, soil ripeness, and distant detecting and UAV symbolism. This audit has laid out the major promising profound learning methods, for example, Articial Neural Network, Convolution Neural Network, Multi-layer insight, Gaussian organization, Bayesian Network, and Long Short-term Memory.

\section{REFERENCES}

[1] Lipper, L., Thornton, P., Campbell, B. M., Baedeker, T., Braimoh, A., Bwalya, M., ... \& Hottle, R. (2014). "Climate-smart agriculture for food security." Nature Climate Change, 4(12), 1068.

[2] Annual report 2017-18, Department of Agriculture, Cooperation \& Farmers Welfare Ministry of Agriculture \& Farmers Welfare Government of India, Krishi Bhawan, New Delhi-110001.

[3] Ray, D. K., Ramankutty, N., Mueller, N. D., West, P. C., \& Foley, J. A. (2012). "Recent patterns of crop yield growth and stagnation." Nature communications, 3,1293.

[4] https://www.researchgate.net/figure/Soil-and-climaticrequirements-of-different-crops-grown-inPunjab_tbl1_226382093

[5] http://ucanr.edu/sites/Nutrient_Management_Solutions / stateofscience/Meet_Crop_Nutrient_Requirements

[6] Basso, B., Cammarano, D., \& Carfagna, E. (2013) "Review of crop yield forecasting methods and early warning systems." In Proceedings of the First Meeting of the Scientific Advisory Committee of the Global Strategy to Improve Agricultural and Rural Statistics, FAO Headquarters, Rome, Italy (pp.18-19).

[7] Forsyth, R. (Ed.). (1989). "Machine learning: Principles and techniques." London: Chapman and Hall.

[8] Kaur, K. (2016). "Machine learning: applications in Indian agriculture." Int. J. Adv. Res. Comput. Commun. Eng.(IJARCCE), 5(4).

[9] https://medium.com/@ariesiitr/an-artificial-neural-netwo rk-ann-is-a-computational-model-that-is-inspired-by-theway-biological-c17b07166d4c

[10] https://www.ibm.com/developerworks/library/cc-machin e-learning-deep-learning-architectures/index.html

[11] Goodfellow, I., Bengio, Y., Courville, A., \& Bengio, Y. (2016). Deep learning (Vol. 1). Cambridge: MITpress.
[12] Villanueva, M. B., \& Salenga, M. L. M. (2018) "Bitter Melon Crop Yield Prediction using Machine Learning Algorithm." (IJACSA) International Journal of Advanced Computer Science and Applications, Vol. 9, No.3.

[13] Wang, A. X., Tran, C., Desai, N., Lobell, D., \& Ermon, S. ,(2018). "Deep Transfer Learning for Crop Yield Prediction with Remote Sensing Data.", In Proceedings of the 1st ACM SIGCAS Conference on Computing and Sustainable Societies (p. 50).ACM.

[14] Mohan, P., \& Patil, K. K. (2018) "Deep Learning Based Weighted SOM to Forecast Weather and Crop Prediction for Agriculture Application.", International Journal of Intelligent Engineering and Systems, Vol.11, No.4.

[15] Oliveira, I., Cunha, R. L., Silva, B., \& Netto, M. A. (2018). "A Scalable Machine Learning System for Pre-Season Agriculture Yield Forecast.” arXiv preprintarXiv: 1806.09244.

[16] Jiang, Z., Liu, C., Hendricks, N. P., Ganapathysubramanian, B., Hayes, D. J., \& Sarkar, S. ,(2018). "Predicting County Level Corn Yields Using Deep Long Short Term Memory Models." arXiv preprint arXiv: 1805.12044.

[17] Chlingaryan, A., Sukkarieh, S., \& Whelan, B. (2018). "Machine learning approaches for crop yield prediction and nitrogen status estimation in precision agriculture: A review.", Computers and Electronics in Agriculture, 151,61-69.

[18] Priya, P., Muthaiah, U., \& Balamurugan, M. (2018) "Predicting Yield Of The Crop Using Machine LearningAlgorithm."InternationalJournalOfEngineeringS ciences\&ResearchTechnology7(4)

[19] You, J., Li, X., Low, M., Lobell, D., \& Ermon, S. (2017).” Deep Gaussian Process for Crop Yield Prediction Based on Remote Sensing Data." AAAI Conference on Artificial Intelligence (AAAI-17) (pp. 4559-4566).

[20] Fourie J., Hsiao J., Werner A, (2017). "Crop yield estimation using deep learning", 7th Asian- Australasian Conference on PrecisionAgriculture.

[21] Bhangale P.P., Patil Y.S., Patil D.D, (2017).” Improved Crop Yield prediction Using Neural Network". IJARIIE Vol-3 (2)(2395-4396).

[22] Cheng,H.,Damerow,L.,Sun,Y.,\&Blanke,M.(2017).“Earlyy ieldpredictionusingimageanalysis of apple fruit and tree canopy features with neural networks." Journal of Imaging, 3(1),6.

[23] Manjula, E., \& Djodiltachoumy, S. (2017)." A Model for Prediction of Crop Yield." International Journal of Computational Intelligence and Informatics, 6(4),2349-6363.

[24] Kim, N., \& Lee, Y. W. (2016). "Machine learning approaches to corn yield estimation using satellite images and climate data: a case of Iowa State." J. Korean Soc. Surv. Geod. Photogramm. Cartogr., 34(4), 383-390.

[25] Shastri, M. S., \& Gunge, A. K. (2016). "Neural Network based Weather Prediction Model towards Ideal Crop Selection." International Journal Of Engineering And Computer Science, 5(9). 